\title{
Fertility decline and the heights of children in Britain, 1886-1938
}

\author{
Timothy J. Hatton ${ }^{\mathrm{a}, *}$, Richard M. Martin ${ }^{\mathrm{b}}$ \\ a Australian National University, Australia, and University of Essex, United Kingdom \\ ${ }^{\mathrm{b}}$ University of Bristol, United Kingdom
}

\section{A R T I C L E I N F O}

\section{Article history:}

Received 28 April 2009

Available online 8 June 2010

\section{JEL classification:}

I32

$\mathrm{J} 13$

N33

N34

\section{Keywords:}

Fertility decline

Heights of children

Health in Britain

\begin{abstract}
A B S T R A C T
In this paper we argue that the fertility decline that began around 1880 had substantial positive effects on the health of children, as the quality-quantity trade-off would suggest. We use microdata from a unique survey from 1930s Britain to analyse the relationship at the household level between the standardised heights of children and the number of children in the family. Our results suggest that heights are influenced positively by family income per capita and negatively by the number of children or the degree of crowding in the household. The evidence suggests that family size affected the health of children through its influence on both nutrition and disease. Applying our results to long-term trends, we find that rising household income and falling family size contributed significantly to improving child health between 1886 and 1938. Between 1906 and 1938 these variables account for 40\% of the increase in heights, and much of this effect is due to falling family size. We conclude that the fertility decline is a neglected source of the rapid improvement in health in the first half of the twentieth century. (c) 2010 Elsevier Inc. All rights reserved.
\end{abstract}

\section{Introduction}

It is now well understood that growth during childhood is conditioned by nutrition and disease. A host of studies in a variety of historical and development settings have explored the link between nutrition and growth, so much so that height has become widely accepted as a key indicator of physiological well-being. It is also widely acknowledged that the disease environment matters: children subject to frequent bouts of disease such as diarrhoea and respiratory infections are less able to convert the available food supply into the growth of bone and sinew. While it is possible to regain lost ground through lengthening the growth years, catching up may be partial and so deficits in nutrition and health can leave a permanent mark on final height. Research by epidemiologists and others has also shown that poor health during childhood and diminished height are correlated with adult health conditions such as ischaemic heart disease and with increased risk of mortality from all causes. ${ }^{1}$

In the past 25 years economic historians have unearthed a vast amount of data on heights that has painted a much clearer picture of long-run trends in the biological standard of living (Steckel, 1995, 2009). For the United States and a number of European countries the results typically show a steady increase in average heights that broadly correlates with the pace of economic development, although with some temporary reverses such as those observed in the United States, Britain, the Netherlands, Sweden and Germany around the middle of the nineteenth century. ${ }^{2}$ The steady growth trend in the late nineteenth century was followed by a much steeper upward trend that started in most countries around the end of the nineteenth century and extended well beyond the Second World War. ${ }^{3}$ The remarkable pace of improvement in the health of children in the first half of

\footnotetext{
* Corresponding author.

E-mail address: hatton@essex.ac.uk (T.J. Hatton).

1 For useful surveys, see Elo and Preston (1992) and Galobardes et al. (2004).

2 See the country studies in Steckel and Floud (1997) and the overview by Haines (2004).

3 The trends for a number of countries are compared in Floud (1994, pp. 16-19) and presented graphically by Weir (1993). More recently, Baten (2007, p. 11) shows that the sharp discontinuity in the trajectory of heights in western Europe and North America around the turn of the 20th century is not paralleled in the populations of other continents.
} 
the twentieth century has been widely attributed to better nutrition as a direct result of the growth in per capita income as well as to public heath improvements, the availability of antibiotics and vaccination, and medical progress more generally. However, there is an issue of timing, as rapid improvements in health often preceded a quickening in the growth of income per capita and they also largely pre-date the expansion of health services and public welfare programs (McKeown et al., 1975).

One factor that has been neglected in much of the debate is the diminishing size of the family resulting from the decline in fertility that began in the late nineteenth century and continued until the $1930 \mathrm{~s} .{ }^{4}$ This trend has been interpreted as the progressive substitution away from large numbers of children per family towards higher average child 'quality'. The preference for quality in dimensions such as health and education over quantity has been linked to trends such as lower infant mortality, restrictions on child labour, the rise of education (especially among parents) and a host of other factors associated with economic development. Clearly, if smaller families are causally linked to improved outcomes for children, then the fertility decline should have been a powerful force for improvement. It is worth stressing that the focus here is exclusively on the effects of changing family circumstances rather than on their causes. ${ }^{5}$

The quality-quantity trade-off has been the subject of a lively empirical debate among economists since the pioneering analyses of Becker and Lewis (1973) and Becker and Tomes (1976). A host of studies have explored the links between childhood conditions and health and educational outcomes using modern microdata, which include, among other explanatory variables, the number of children in the household. Although there are issues of causal inference, the weight of evidence favours a negative relationship between the number of siblings and the average child outcome. ${ }^{6}$ In this light it is surprising that so little attention has been paid to this key relationship in explaining the dramatic improvements in health from the end of the nineteenth century.

Empirical analysis of country-level data has firmly established the historical link between income per capita and the heights of young adults (Floud, 1994; Steckel, 1995). Other variables matter too, including inequality and, interestingly, infant mortality both of which have negative effects. The latter finding points to the importance of the disease environment in conditioning growth, and the decline in infant mortality has sometimes been related to the decline in fertility. One of the few studies to make the direct link between fertility and height is Weir (1993) who analysed regional data on the heights of French conscripts from 1840 to 1911. Using this panel he found that, in the presence of other effects, falling marital fertility contributed half to three quarters of a centimetre to the increase in heights across the nineteenth century. This accounts for about a quarter of the total gain in height between 1790 and 1911. Although contributions such as these that rely on aggregate data have added much to our understanding, by their very nature, they are unable to identify the mechanisms at work at the household level.

Some of the literature also studies heights at the individual level. ${ }^{7}$ Broadly speaking, the results indicate that height is positively associated with income or occupational status and with rural residence. Apart from the well-known selection issues that confront the use of data on military recruits, these studies typically suffer from a number of other shortcomings. The most important is that the information available for use as explanatory variables is often severely limited. Apart from age, the explanatory variables used often relate to occupation or father's occupation, literacy, place of birth and a few other individual characteristics. These variables stand as proxies for variables, such as family income, that are not directly observed. A second issue is that individuals are often observed as adults and so assumptions have to be made about the conditions in which they grew up. Given these limitations it is perhaps not surprising that household characteristics such as the number of siblings have been neglected and that, as a result, the potential impact of changing family size has been largely obscured.

This paper offers new results using household data on the heights of children in British families during the 1930s. This allows us to pursue the type of microeconomic analysis that is used by economists on modern datasets but for a period much closer to the fertility decline. We find that the heights of children are positively related to family income per capita and negatively to the number of children in the household. The key channels of influence appear to be nutrition, as represented by food expenditure, and the disease environment, which is related to overcrowding and housing quality. Using these results we can assess the contribution of falling family sizes to the trend in the heights of children from the 1880s to the 1930s. The bottom line is that falling family size accounts for more than a third of the increase in heights over this period.

\section{Trends in health, height and socioeconomic conditions}

Height data for Britain come from a variety of sources and those most relevant to our argument are listed in Table 1 . They are reported by date of observation rather than by date of birth. Those for army recruits (adjusted for truncation) show that, after some decline, average heights increase by about $1 \mathrm{~cm}$ per decade from 1885-9 to 1910-13. This would be equivalent to an increase of about $0.8 \mathrm{~cm}$ per decade for 10 year-old children. The upper right hand panel of Table 1 illustrates the trend in heights among boys at Christ's Hospital School, which shows that from the 1870s to the 1910s heights increase at about $0.6 \mathrm{~cm}$ per decade for 10 year olds and $0.9 \mathrm{~cm}$ per decade for 14 year olds. It also illustrates the distinct acceleration in heights referred to earlier. From $1906-18$ to 1930-33 heights increase by $1.6 \mathrm{~cm}$ per decade for 10 year olds and by as much as $2.2 \mathrm{~cm}$ for 12 year olds and $2.8 \mathrm{~cm}$ for 14 year olds. ${ }^{8}$

\footnotetext{
${ }^{4}$ One important exception is Reves (1985) who argued that declining fertility played a significant role in reducing infectious disease among children in England and Wales from the late nineteenth century.

5 There is an extensive literature on the factors influencing the choice of smaller families, which include expanding consumption possibilities, increasing education, and changing social norms. Recent important contributions on Britain include Garrett et al. (2001), Humphries (2007) and Scott (2008).

${ }^{6}$ For the effects on education see Hanusheck (1992), and Booth and Kee (2009).

7 Studies that present individual-level econometric analysis of heights include Johnson and Nicholas (1997), Whitwell et al. (1997), and Riggs (1994).

8 Christ's Hospital is a charitable school for poor and fatherless children that received a royal charter from Edward VI shortly after its foundation in 1552 . The basic criteria for admission remained largely unchanged over the period examined here and so the trend in heights should not be influenced by changing socioeconomic mix among the pupils.
} 
Table 1

Heights of army recruits and school children, 1860-1939.

\begin{tabular}{|c|c|c|c|c|c|c|}
\hline \multicolumn{3}{|c|}{ Army recruits } & \multicolumn{4}{|c|}{ Christ's Hospital boys } \\
\hline & Age 18 & Age 20 & & Age 10 & Age 12 & Age 14 \\
\hline $1860-64$ & 166.1 & 167.1 & $1870 s$ & 130.1 & 137.8 & 146.4 \\
\hline $1880-84$ & 164.3 & 166.1 & 1906-18 & 132.7 & 140.4 & 149.9 \\
\hline $1885-89$ & 162.3 & 165.9 & 1919-22 & 132.4 & 142.4 & 152.0 \\
\hline $1890-94$ & 162.8 & 166.9 & $1923-26$ & 135.4 & 143.5 & 154.0 \\
\hline 1895-99 & 163.1 & 167.1 & $1927-30$ & 135.7 & 143.6 & 154.7 \\
\hline 1900-04 & 163.8 & 166.9 & 1930-33 & 136.0 & 145.3 & 155.6 \\
\hline 1905-09 & 164.3 & 168.7 & & & & \\
\hline $1910-13$ & 164.8 & 168.1 & & & & \\
\hline \multicolumn{7}{|c|}{ School children in British towns } \\
\hline & Boys 5 & Boys 8 & Boys 12 & Girls 5 & Girls 8 & Girls 12 \\
\hline $1908-11$ & 101.4 & 117.4 & 135.0 & 101.0 & 114.9 & 135.2 \\
\hline $1912-15$ & 101.9 & 118.3 & 134.9 & 101.8 & 117.2 & 135.5 \\
\hline 1916-19 & 102.2 & 119.2 & 135.6 & 102.2 & 117.3 & 135.4 \\
\hline $1920-23$ & 103.1 & 119.7 & 135.3 & 102.5 & 118.8 & 135.9 \\
\hline $1924-27$ & 104.0 & 121.0 & 136.4 & 103.4 & 119.6 & 137.3 \\
\hline $1928-31$ & 104.1 & 121.8 & 137.9 & 104.2 & 120.5 & 138.6 \\
\hline $1932-35$ & 104.8 & 123.1 & 139.0 & 104.7 & 121.3 & 139.8 \\
\hline 1936-39 & 105.7 & 123.7 & 139.6 & 105.5 & 122.4 & 141.1 \\
\hline
\end{tabular}

Notes: Heights of army recruits (adjusted for truncation) from Rosenbaum (1988), Table 1 p. 282; heights of boys at Christ's Hospital from Rosenbaum (1988), Table 8 p. 288. Heights of school children in British towns calculated from data collected by Bernard Harris and supplied by the AHDS at the University of Essex. The underlying data is an unbalanced panel of average heights by age and by town. The figure calculated for each year, is based on the coefficients on the year dummies in regressions for each age and sex, which include town fixed effects. The regressions also include an adjustment for the difference between the year of age and the estimated average age of the children in each observation (i.e. if the average age of eight-year olds in a given observation is 8.5 then the variable takes the value 0.5). The omitted category (the intercept) is Aberdeen in 1908

For the period from 1908 we are fortunate to have more representative data on the heights of children that have been carefully assembled by Bernard Harris from the reports of school medical officers (see Harris, 1994, 1995). The practice of measuring children dates from the establishment of the school medical service in 1908 and was continued into the 1950s. As the results were not reported for all ages in all towns in all years, we have used fixed effects regressions with year dummies to establish the trends in heights for boys and girls at ages 5, 8 and 12. The four-year averages presented in the lower panel of Table 1 also show remarkably strong growth in average heights over three decades up to 1939. Linear trends fitted to the underlying annual data give the average annual increase in height for boys of $1.5 \mathrm{~cm}$ per decade for five year olds, $2.5 \mathrm{~cm}$ per decade for eight-year olds and $1.9 \mathrm{~cm}$ per decade for 12 year olds. For girls, the average increases per decade at the three ages are, respectively, $1.6 \mathrm{~cm}, 2.5 \mathrm{~cm}$ and $2.3 \mathrm{~cm}$. These figures reinforce the impression gained from more fragmentary data that the heights of children increased particularly rapidly from around the turn of the century. ${ }^{9}$

An alternative indicator that is often seen as a general measure of the health status of populations is infant and child mortality. While infant mortality indirectly reflects nutritional status, it is generally taken as more closely reflecting the disease environment. As Fig. 1 shows, infant mortality in England and Wales averaged about 150 per thousand in the late nineteenth century after which it went into a sharp secular decline in the first half of the twentieth century, reaching about a third of its former level by the late 1940s (Registrar General, 2004, Table 4, p. 5). Among the proximate causes of the steep fall in infant mortality were diseases associated with prematurity, diarrhoea and dysentery as well as respiratory diseases such as bronchitis, pneumonia and influenza. Woods et al. (1988, p. 362) argue that the upturn around the turn of the century was largely due to unusual climatic conditions, which particularly affected deaths from diarrhoea and that the underlying trend decline dates from the early 1890s.

Mortality rates for children aged 1-4 and 5-9 declined from the middle of the nineteenth century, largely as a result of the declining incidence of diseases such as scarlet fever, diphtheria, measles and whooping cough. Floud et al. (1990, p. 301) comment on the relationship between cohort mortality and the trends in heights in the half century to 1914 as follows: "The match is amazingly close. In other words, the fall in mortality in late nineteenth century England and Wales follows almost exactly the pattern that we would expect from the evidence of nutritional status. The height data make the link between nutrition (although in a wider sense) and mortality which McKeown (1976) could only infer." They go on to comment that the decline in mortality and the increase in the heights of successive cohorts "could best be explained by improvements in the health of children" (Floud et al., 1990, p. 314). Thus it appears that while improved nutrition underpinned the trend increase in height and the trend fall in child and adult mortality from the third quarter of the nineteenth century, significant improvements in the disease environment affecting children (as reflected in infant mortality) date largely from the 1890 s.

\footnotetext{
${ }^{9}$ This is consistent with other data presented by Rosenbaum (1988) and earlier studies by Karn (1937), Clements (1953) and Boyne et al. (1957). For a longerterm perspective see Floud et al. (1990, p. 166).
} 


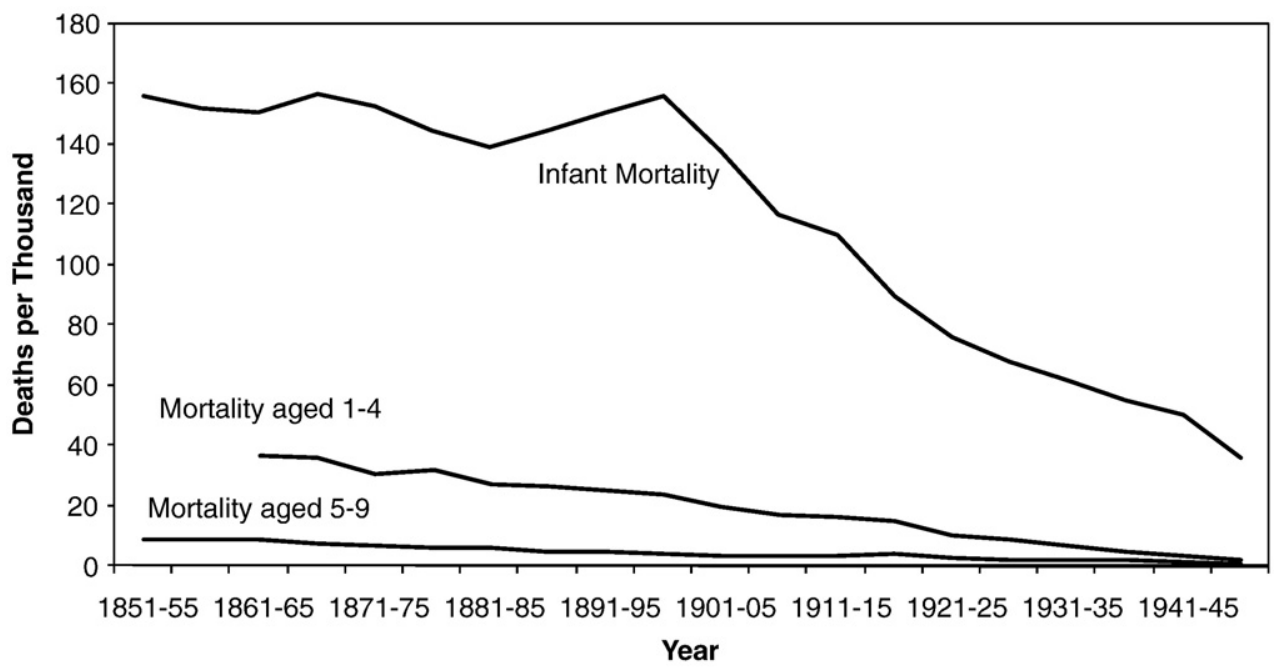

Source: Registrar General (2004), Table 4, p. 5.

Fig. 1. Infant and child mortality rates: England and Wales, 1851-1950.

The argument put forward here is that these striking improvements in the health of children owe much to the fall in the number of children per family. Although the fall in infant and child mortality increased the survival rate, this effect on family size was overwhelmed by the falling birth rate. Fig. 2 shows that births per woman aged 15-44 fell from a peak of 154 per thousand in the 1870s to a low of 62 per thousand in the 1930s (OPCS, 1987, Table 1.4, p. 26). Over the same interval the total period fertility rate fell from 4.8 to 1.7 while the gross reproduction rate fell from 2.3 to 0.9 . The clear implication of these trends is smaller families, particularly among the working class where the fertility decline was later and steeper.

Much of the literature on health and height-most notably that inspired by the pioneering work of McKeown (1976) and Fogel (2004)-has stressed the importance of the link with real wages and per capita income. And most of the focus has been on the nineteenth century, with an emphasis on nutrition and only indirectly on the disease environment. Such a focus is difficult to square with the British experience between 1850 and 1950. Feinstein's (1995) figures show that real earnings increased by $1.2 \%$ per annum in 1875-1900, $0.8 \%$ in 1900-1925 and 1.6\% in 1925-1950. Overall the average rate of wage increase was the same in the half centuries before and after 1900. However, for families with children, household income per capita grew more strongly than real wage rates between the 1880s and the 1930s because of the fall in family size.

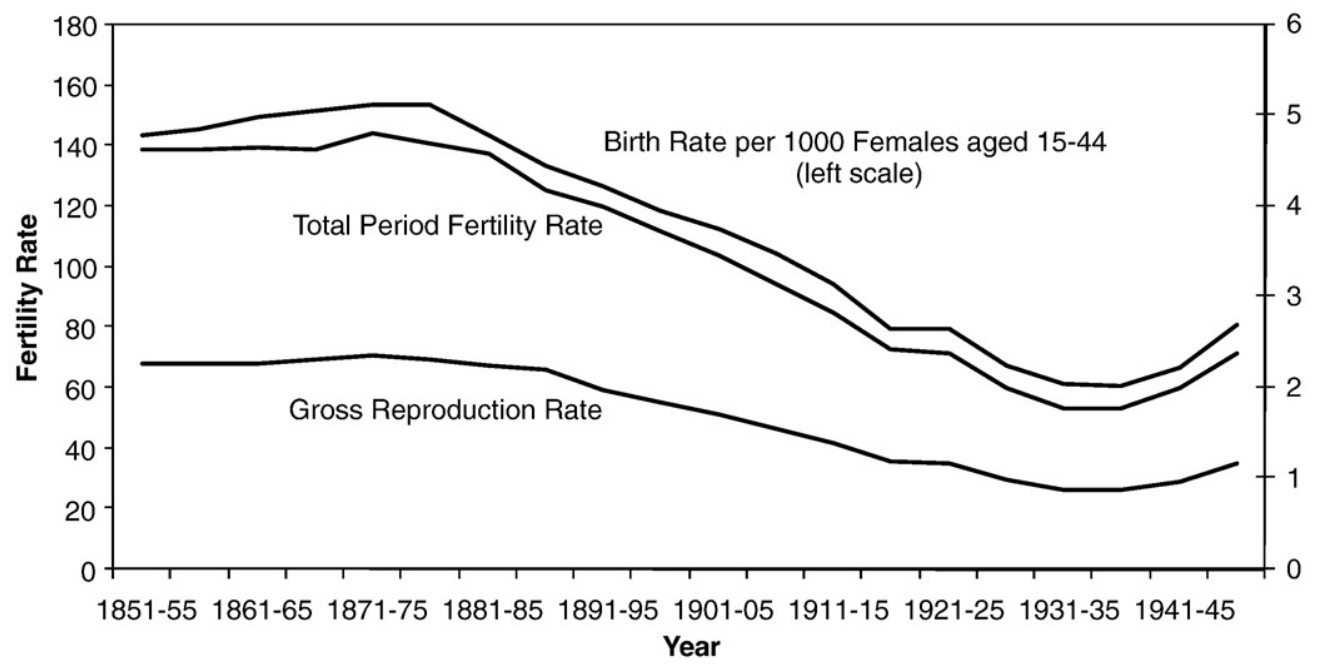

Source: OPCS (1987), Table 1.4, p. 26.

Fig. 2. Fertility rates, England and Wales 1851-1950. 
These trends, particularly after the turn of the century, are consistent with the sharp decline in poverty among working class families that was noted in a variety of poverty surveys. In his investigation of York in 1899, Rowntree (1901, p. 37) found that large families with young children were particularly likely to be in poverty. In his later survey he found that the fall in primary poverty between 1899 and 1936 was principally due to the increase in wages for the low paid and the decrease in large families (meaning those with more than three children). Rowntree found that the primary poverty rate for children under 14 in working class families fell from about $30 \%$ in 1899 to $13 \%$ in 1936 , while their share of those in poverty fell from $58 \%$ to $47 \%$. Using more generous poverty standards, the child poverty rate fell from $55 \%$ to $43 \%$ while their share of total poverty fell from $38 \%$ to $34 \%$. ${ }^{10}$

A number of studies have examined the environmental conditions associated with disease and mortality. These conditions include the well-known differences between urban and rural localities, population density, industrial or occupational structure and the sanitary infrastructure of towns (Woods et al., 1988; Lee, 1991; Millward and Bell, 1998; Williamson, 1990, Ch. 9). Such variables are often interpreted as proxies for sanitary conditions generally and clean water supply in particular. ${ }^{11}$ The evidence for British towns suggests that the sanitary infrastructure improved particularly rapidly from the end of the nineteenth century (Bell and Millward, 1998). This positive effect on the health environment eventually outweighed the negative effect of continuing urbanisation.

The degree of overcrowding also appears to have a strong negative effect on health as measured by infant mortality, suggesting that conditions within the household were important. Overall, housing conditions improved, especially after the turn of the century, both in terms of quality and overcrowding. In York, the proportion of the working class population living in overcrowded conditions (defined as more than two persons per room) fell from 10.1\% in 1899 to 3.6\% in 1936 (Rowntree, 1941 , p. 269). Examining trends in Glasgow and Edinburgh, Cage and Foster (2002) found a positive effect of overcrowding on infant mortality, an effect that diminished sharply between 1911 and $1931 .^{12}$ Below we offer further evidence that, through its effect on overcrowding, declining family size significantly improved health outcomes for children.

One factor that cannot account for much of the improvement in the disease environment is the discovery and dissemination of new medical treatments. As McKeown (1976) has shown, many of the landmark medical discoveries of the twentieth century did not become available until around the Second World War. Streptomycin (effective against tuberculosis) was introduced in 1947, sulphonamides and sulphapyridine (effective against bronchitis, pneumonia and influenza and whooping cough) not before 1938 and antibiotics still later. Similarly, treatments for other childhood diseases such as measles and scarlet fever were developed in the 1930s, long after the steep decline in these diseases. Only the timing of the reduction in diphtheria mortality from around the turn of the century seems be consistent with the advent of treatment by antitoxin.

A more recent line of research suggests that advances in health technology at the domestic level were far more important. Mokyr (2000) argues that improved knowledge of nutrition and the channels through which disease is transmitted led mothers to devote more time and effort to child nurturing and housework than they otherwise would have. Specific improvements identified in the literature include better quality milk supplies, better knowledge of hygiene and feeding methods (particularly bottle feeding) as well as the growing importance of local health services in the form of midwives and health visitors, and not least of all the health of the mothers themselves (Dyhouse, 1978; Fildes 1998; Millward and Bell, 2001). These advances are likely to have been all the more effective when taken in conjunction with smaller families. Indeed, the quality-quantity trade-off suggests that smaller family size was a key factor that made possible such improvements in child-nurturing practices.

\section{The Boyd Orr cohort}

In order to shed more light on the relationships between health, income and family size, we draw on the records from the Boyd Orr survey. This inquiry was undertaken in 1937-9 by the Rowett Research Institute at Aberdeen, led by Sir John Boyd Orr. ${ }^{13}$ It represents the culmination of a line of social investigation originating in the late nineteenth century that focused on the relationship between poverty and life chances. It is one of the few interwar surveys for which the original records have survived and the only one that contains information on the heights and health of children. The original survey covered a total of 1343 households containing 4999 children under the age of 19. It was confined to families with children and it was targeted to overrepresent poor families. 16 different towns and villages where chosen and these were intended to be representative of urban and rural locations. ${ }^{14}$

The original survey recorded the number of children and total household members with details of income, food expenditure and housing conditions. The clinical part of the survey collected a variety of indicators of the anthropometric and health status of

\footnotetext{
${ }^{10}$ The primary poverty line was defined by Rowntree (1901, p. 86) as a living standard sufficient merely to maintain physical efficiency. The figures in the text for primary poverty are calculated from the comparative data given by Rowntree (1941, p. 110). The higher poverty lines are, for 1899 , primary plus secondary poverty and, for 1936, the 'human needs' standard. These are not strictly comparable.

11 Cutler and Miller (2005) show that the introduction of clean water supplies account for up to half of the mortality decline in major US cities between 1900 and 1940. See also Preston and Haines (1991).

${ }^{12}$ For a comparison with Sydney, Australia, see Jackson and Thomas (1995).

13 The work on the survey was interrupted by the War and the report summarizing the results was not published until 1955 (Rowett Institute, 1955). The original survey records were recovered and have been augmented with follow-up information on later life outcomes by epidemiologists in the Department of Social Medicine, University of Bristol.

${ }^{14}$ The 16 locations are, in Scotland: Aberdeen, Kintore, Hopeman, Barthol Chapel, Methlick, Tarves, West Wemyss, Coaltown of Wemyss, Dundee and Edinburgh; and in England: Barrow-in-Furness, Liverpool, Yorkshire, Wisbech, Fulham and Bethnal Green. These locations are identified on a map in Martin et al. (2005), p. 743.
} 


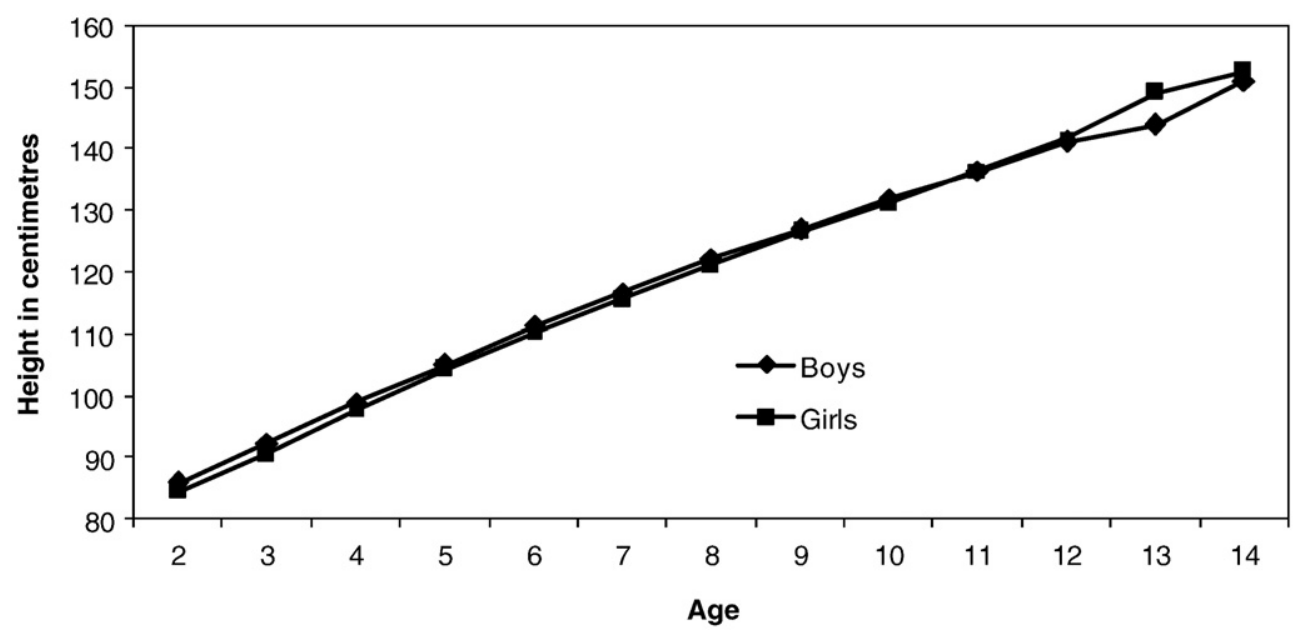

Fig. 3. Height by age of boys and girls in the Boyd Orr cohort.

the children including height, leg length, weight, incidence of medical conditions and dental decay. The clinical survey did not include all the households nor did it cover all children in households that are represented. ${ }^{15}$ As compared with the original sample the clinical survey under-represents infants, those over age 14 and, most important, those in certain locations. Here we focus on children aged 2 to 14 for whom height and weight measurements are available for 2946 children in 1131 households in 14 of the 16 localities. ${ }^{16}$

The heights by age of boys and girls are plotted in Fig. 3. They increase fairly linearly from around $85 \mathrm{~cm}$ at age 2 to $152 \mathrm{~cm}$ at age 14 , or about $5.6 \mathrm{~cm}$ per year of age. Some of the other characteristics of those who were measured appear in Table 2 , which lists the means across individuals and the means across households. The average age of the children is 7 years and 11 months and a little over half are female. The average child comes from a family with 4.56 children and 6.75 people in total, whereas the average family consists of 3.74 children and 5.79 persons. As we show below, these families are much larger than the typical working class family with children in 1938. In this respect the households in the Boyd Orr cohort have a demographic structure that is more representative of about 30 years earlier. ${ }^{17}$

Weekly per capita income of each household was recorded by the survey only as a categorical variable, with four categories: less than 10 shillings, $10-15$ shillings, $15-20$ shillings and greater than 20 shillings. Similarly per capita food expenditure is grouped into four categories: less than 5 shillings, 5-7 shillings, 7-9 shillings and greater than 9 shillings. An income of less than ten shillings per family member was considered as living in poverty by the standards of the time. Boyd Orr (1936, p. 49) found that children below this poverty line had a food intake that was deficient in almost every constituent while those in the next income bracket suffered deficiencies mainly in certain minerals and vitamins.

As Table 2 shows $71.6 \%$ of children and $59.8 \%$ of families were below this poverty line and $54.8 \%$ of children and $43.6 \%$ of families subsisted on a food intake costing less than 5 shillings per week. Applying a similar poverty line Rowntree (1941, pp. 42, 144-149) found that, in York (a fairly typical town) in 1936, 37\% of working class households and $43 \%$ of children under 14 were in poverty. In this respect too, those families observed in the Boyd Orr survey are more typical of working class households 30 years earlier. Thus, while the population in the Boyd Orr survey is somewhat unrepresentative of the later 1930s, this is a strength for the purposes of comparison with earlier decades.

The survey also collected a limited amount of information on living conditions in the household, including the number of persons per room. $42 \%$ of these households were living in overcrowded conditions, on the widely used criterion of more than two persons per room. The investigators also gave an assessment of the general level of cleanliness of the dwelling, ranking a third of them as good or excellent and the remainder moderate or poor. Only $37 \%$ of the dwellings possessed a flush toilet inside with the remainder being non-flush and/or outside. Finally, nearly three quarters of dwellings were assessed as having good or excellent ventilation, with the rest designated as moderate or poor.

\footnotetext{
${ }^{15}$ The survey report is somewhat vague on this point, commenting that "For various reasons all children in all surveyed families could not be examined although the attempt was made to include them all" (Rowett Institute, 1955, p. 50). One difficulty seems to have been arranging attendance at a school or clinic where measuring instruments could be used. But another seems to have been simply a matter of logistics: two of the original locations (Edinburgh and Kintore) are not represented at all in the clinical survey. These two locations account for about $40 \%$ of the missing observations for children aged $2-14$.

${ }_{16}$ According to the original survey report 3762 children were examined, and the records for most of these have been found. We exclude those under age 2 and over 14 because they are underrepresented and may be subject to selection bias, and also because the height measurements for the very young children are thought to be less reliable.

${ }^{17}$ One reason for this is that almost all the families have at least one child of school age. We suspect that this is because families were contacted by first approaching the schools.
} 
Table 2

Characteristics of children who were measured in the Boyd Orr survey.

\begin{tabular}{lcc}
\hline & By individual \\
\hline No of cases & 2946 \\
Individual characteristics & 7.92 \\
$\quad$ Average age & 52.7 \\
$\quad$ Percent female & \\
Household characteristics & 4.56 \\
Number of children in family & 6.75 \\
Family size & 71.56 \\
Family income per capita $<10 \mathrm{~s}$ & 54.75 \\
Food expenditure per capita $<5 \mathrm{~s}$ & 43.76 \\
Persons per room $>2$ & 32.96 \\
Clean house & 39.8 \\
Flush toilet inside & 43.50 \\
Good ventilation & 42.01 \\
\hline
\end{tabular}

Note: Due to missing data some of the means are calculated on a smaller number of observations as follows (individuals, households): income per capita (2911, $1112)$, persons per room $(2605,984)$, clean house $(2734,1045)$, flush toilet $(2099,786)$, and good ventilation (2707, 1037).

\section{Family-level determinants of heights}

For the purposes of analysis we standardise the heights of children in the Boyd Orr cohort by age and sex by converting them to $z$-scores. The $z$-score converts heights into units of standard deviation by taking the deviation of the individual's height from the median and dividing by the standard deviation for that age/sex category. Thus the mean z-score is approximately zero and the standard deviation is approximately one. In order to measure the family-level determinants of heights we estimate a cross sectional model in which the dependent variable is the average $z$-score of height for the children who were measured in each household. Thus we do not explain differences between the heights of siblings, as our explanatory variables are family level only.

The recent debate in the economic literature noted above has been much concerned with avoiding biases that might arise from unobserved factors that determine both the health, as represented by height, and the number of children in the family. One solution is to use instrumental variables in order to correct any bias that arises from correlation between one or more of the explanatory variables and the error term. Here we present both ordinary least squares and instrumental variables estimates. The issue of endogeneity is explored in more detail in another paper (Hatton and Martin, 2010). ${ }^{18}$ Later we shall use these estimates to construct counterfactual trends and our purpose here is to insure against relying on coefficients that are biased in favour of our hypothesis.

The instruments used are of three types. The first is a dummy variable for families that contain twins at last birth. The incidence of twins has often been used as an instrument for family size, on the argument that the birth of twins is an exogenous influence on the number of children. However families that choose more births are more likely to have a twin birth, so the incidence of any twin birth is naturally correlated with family size. It is therefore necessary to create the dummy for a given parity (in this case last birth) in order to avoid reverse causality. In the regression analysis that follows the twins themselves (who are significantly shorter) are dropped from the analysis, so that the instrument relates to other children in families that have experienced a shock to family size.

The second instrument is the average weekly income for the occupational class of the head of household ( 6 classes) constructed using national estimates reported by Routh (1965, p. 104). This is strongly correlated with the household's income but excludes heterogeneity at the household level. Other instruments are based on the household's location and include the share of the labour force in agriculture and the share of population urban, based on county level data from the census. These variables capture wellknown income differences between rural and urban locations as well as reflecting different local health environments. In order to capture current economic conditions we also include the local unemployment rate for 1937-9 as reported by the Ministry of Labour. The first stage estimates for income per capita and the number of children are reported in Appendix A. Twins at last birth is highly significant in both equations, despite the fact that there are only 21 such families in the data, and the other variables give the expected signs. Both equations pass the conventional F-test for the relevance of the instruments $(\mathrm{F}>10)$.

Table 3 reports a set of regressions of the average height $z$-score across families in the Boyd Orr cohort. The first two columns show the effect of per capita income alone. The OLS estimate indicates that moving up one income class increases the height of children in the family by a third of a standard deviation or about $2 \mathrm{~cm}$ for an 8 -year old. When instrumental variables are used, the coefficient increases slightly in size and remains highly significant. It is worth noting that the test for endogeneity suggests that income per capita is endogenous but the overidentification test is right on the margin of 5\% significance, suggesting that some of the instruments may have a direct effect, rather than working only through their effect on income per capita.

\footnotetext{
18 The basic model is written as $\bar{q}_{j}=\beta\left(\bar{z}_{j}+\alpha N_{j}\right)+u_{j}$, where $\bar{q}_{j}$ is the average 'quality' of children in household $j$, in this case the average $z$-score for height. Averaging by family abstracts from systematic birth order effects and random individual-specific effects which are interpreted as variations around the family mean. Thus we do not conflate birth order (which across individuals is correlated with family size) and family size. $\bar{z}_{j}$ is average resources per child in family $j$, and $N$ is the number of children. $\beta$ is expected to be positive and $\alpha$ will be positive if there are economies of scale in the production of child quality or negative if there are diseconomies of scale. The endogeneity issue arises if there is an unobserved component of the family-specific disturbance $u_{j}$ that is also correlated with $\bar{z}_{j}$ or $N_{j}$.
} 
Table 3

Effect of per capita income and number of children on height.

\begin{tabular}{|c|c|c|c|c|}
\hline & OLS & IV & OLS & IV \\
\hline Constant & $-0.41^{* *}(8.1)$ & $-0.56^{* *}(6.3)$ & $-0.03(0.3)$ & $0.16(0.4)$ \\
\hline Income per capita & $0.32^{* *}(11.7)$ & $0.42^{* *}(8.2)$ & $0.26^{* *}(8.5)$ & $0.29 * *(3.8)$ \\
\hline No. of children in family & & & $-0.07^{* *}(5.0)$ & $-0.14^{*}(2.0)$ \\
\hline $\mathrm{R}^{2}$ & 0.13 & 0.13 & 0.14 & 0.13 \\
\hline $\mathrm{F}$ & 135.8 & 66.4 & 80.4 & 34.8 \\
\hline Endogeneity & & 0.03 & & 0.05 \\
\hline Overidentification & & 0.05 & & 0.11 \\
\hline No. families & 1102 & 1102 & 1102 & 1102 \\
\hline
\end{tabular}

Note: ' $t$ ' statistics in parentheses computed from robust standard errors. ${ }^{* *}=$ significant at $1 \%{ }^{*}=$ significant at $5 \%$. The number of observations is reduced from that in Table 1 because of the exclusion of twins and missing data for income class. Endogeneity and overidentification are the p-values for the Hausman and Hanson J tests respectively.

Table 4

Effect of per capita income and number of children on height by birth order.

\begin{tabular}{|c|c|c|c|c|}
\hline & Birth order 1 & Birth order 2 & Birth order 3 & Birth order 4 \\
\hline Constant & $-0.11(0.2)$ & $0.05(0.4)$ & $-0.26(1.5)$ & $0.06(0.3)$ \\
\hline Income per capita & $0.26^{* *}(6.0)$ & $0.28^{* *}(6.7)$ & $0.29 * *(5.3)$ & $0.26^{* *}(3.0)$ \\
\hline No. of children in family & $-0.05^{*}(2.0)$ & $-0.10^{* *}(4.3)$ & $-0.05 \dagger(1.8)$ & $-0.08^{* *}(2.7)$ \\
\hline $\mathrm{R}^{2}$ & 0.09 & 0.13 & 0.07 & 0.05 \\
\hline $\mathrm{F}$ & 36.2 & 52.0 & 20.2 & 8.8 \\
\hline No. children & 738 & 729 & 577 & 378 \\
\hline
\end{tabular}

Note: 't' statistics in parentheses. ${ }^{* *}=$ significant at $1 \% ;{ }^{*}=$ significant at $5 \% ; \dagger=$ significant at $10 \%$. Twins are excluded.

The third and fourth columns test the hypothesis that the number of children in the family has an effect on health in addition to its effect on income per capita. Since per capita income is not adjusted by an equivalence scale this might induce a positive bias in the coefficient on the number of children. The coefficients in columns (3) and (4) are negative, suggesting that there is some crowding effect on height over and above that which results from the dilution of income per capita. Note also that the IV coefficient is larger than the OLS coefficient, suggesting that the negative coefficient is not simply the result of some unobserved behavioural factor which leads both to smaller families and to healthier children. Although statistical significance is somewhat weaker in the IV estimate, the important point is that the OLS coefficients do not seem to be biased towards zero. Note also that the test for endogeneity is now only marginal but that, with the additional variable, the regression now passes the overidentification test.

It is possible that the effects of family size are driven predominantly by large families. Since the number of children in the households under study ranges from one to eleven it is possible to test this hypothesis. Adding the squared number of children to the regression in column 3 of Table 3 produced a coefficient (not shown) of 0.004 (' $t$ ' $=0.88$ ), which rejects the hypothesis of a non-linear effect. An alternative variant of this test is to see if the family size effect differs depending on the birth order of the child. Table 4 provides OLS estimates of height $z$-scores by parity, so that the dependent variable is now an individual child rather than the average for the family. The results show that per capita income effects are remarkably stable across different birth orders. It also shows that the family size effect is always negative. Although the size and significance of the coefficient vary across parities, there is no evidence of a trend.

A number of other robustness checks were made on the regression in column (3) of Table 3. It is possible that the effect of per capita income diminishes as income increases. Adding the square of income per capita produces a positive but insignificant coefficient of 0.03 (' $\mathrm{t}$ ' $=0.18$ ), which does not support the hypothesis of a non-linear effect. But since income per capita is a categorical variable this is not a very strong test. Another possibility is that the effect of poverty bites harder the more children there are. However, there is no support for this hypothesis as the interaction of income per capita and the number of children gives a negative coefficient ( $\mathrm{t}$ ' $=1.1$ ). Finally, similar results to those in Table 3 were obtained when the dependent variable is the $z$-score of leg length rather than total height. ${ }^{19}$

We can probe a little deeper into the proximate determinants of height by replacing income and the number of children by household food expenditure per capita and the degree of crowding in the household as measured by persons per room. Food expenditure and crowding are chosen subject to the household's overall budget constraint, which is determined by income and family size. For this reason we exclude income and the number of children when examining the effects of these more proximate determinants. It is interesting to note how closely the key elements of the budget constraint are related to the more proximate determinants of health. Regression analysis shows that food expenditure is positively related to per capita income (' $t$ ' $=31.4$ ) and negatively related to the number of children (' $\mathrm{t}$ ' $=10.7$ ), while persons per room is negatively related to per capita income $(' t '=6.9)$ and positively related to the number of children ( $\mathrm{t}$ ' $=15.3$ ).

\footnotetext{
${ }^{19}$ If anything, the effect of family size on leg length is even greater than on total height. Previous analyses of leg length in the Boyd Orr cohort, including a link to longevity, can be found in Gunnell et al. (1998a,b).
} 
Table 5

Effect of per capita food expenditure and housing conditions on height.

\begin{tabular}{|c|c|c|c|c|}
\hline & OLS & OLS & OLS & OLS \\
\hline Constant & $-0.24^{* *}(2.6)$ & $-0.55^{* *}(3.9)$ & $0.63^{* *}(2.9)$ & $-0.68^{* *}(4.1)$ \\
\hline Per capita food expenditure & $0.27^{* *}(8.9)$ & $0.27^{* *}(2.9)$ & $0.27^{* *}(7.8)$ & $0.26^{* *}(8.6)$ \\
\hline Overcrowding (persons per room) & $-0.09^{* *}(3.2)$ & $-0.07^{* *}(2.9)$ & $-0.08^{* *}(2.6)$ & $-0.06^{*}(2.2)$ \\
\hline Cleanliness index & & $0.13^{* *}(2.8)$ & $0.04(0.7)$ & \\
\hline Flush toilet inside & & & $0.003(0.1)$ & \\
\hline Good ventilation & & & $0.10(1.6)$ & $0.16^{* *}(3.1)$ \\
\hline $\mathrm{R}^{2}$ & 0.14 & 0.14 & 0.16 & 0.14 \\
\hline $\mathrm{F}$ & 64.1 & 45.7 & 24.8 & 45.2 \\
\hline No. families & 978 & 953 & 737 & 946 \\
\hline
\end{tabular}

Note: 't' statistics in parentheses computed from robust standard errors. ${ }^{* *}=$ significant at $1 \%$; $^{*}=$ significant at $5 \%$. The number of observations is reduced from that in Table 1 because of the exclusion of twins and missing data for expenditure class and persons per room.

The OLS result in the first column of Table 5 shows that per capita food expenditure has a positive effect on height while overcrowding has a negative effect. The latter is somewhat parallel with the results on the number of children in Table 3 , and it suggests that overcrowding is one channel through which the number of children in the family negatively affects the height of the average child. Thus it is consistent with the literature that suggests that overcrowding worsens the disease environment, which in turn leads to poorer health outcomes. ${ }^{20}$

The second column of Table 5 adds the index for the investigators' assessment of the cleanliness of the household. This has a positive effect as might be expected, but with only marginal effects on the other coefficients. Consistent with the disease interpretation, the result indicates that negative health effects are associated both with the degree of overcrowding and with the general lack of cleanliness of the household environment. When two dimensions of housing quality are added they add little to the explanatory power and the cleanliness index also becomes insignificant. However, when good ventilation is the only variable representing the household environment, it takes a significant positive coefficient. It seems likely that good ventilation reflects the overall quality of the house by capturing the distinction between dark, dingy tenements and more modern housing. Together the results in Table 5 suggest that the fabric of the building may have been one of the main factors contributing to household squalor while the particular facilities that it contained played a secondary role.

\section{Disease and socioeconomic conditions}

The effects of overcrowding and cleanliness on heights provide strong circumstantial evidence that disease was one of the important mechanisms through which low income, and especially large families, negatively affected the health of children. Studies of the links between height and diseases point to the importance repeated respiratory and gastrointestinal infections. Rona and Florey (1980) found that British children with respiratory infections in the preceding year were around 0.4 standard deviations shorter. In their survey of the effects of microbial infection on human height Beard and Blaser (2002, p. 486) give the example of the bacterium Helicobacter pylori the transmission of which is related to the number of children living in the household. ${ }^{21}$ Here we provide further corroborative evidence by focusing directly on the results of clinical examinations that were reported in the Boyd Orr survey. These clinical examinations included taking a blood sample, assessing various skeletal abnormalities, as well as identifying various types of infection. All the clinical observations were made by two doctors using a common standard to minimise the degree of subjectivity involved in making comparisons across individuals. ${ }^{22}$

It is worth stressing, however, that results are limited in two important respects. First, they do not include some of the most important illnesses that would have attenuated growth, either by reducing food intake or by limiting the ability to convert nutrients into building bone and tissue. These include recurrent conditions such as diarrhoea and dysentery, as well as major illnesses such as tuberculosis, whooping cough, scarlet fever, chickenpox and measles. Thus, while we can explore links between household conditions and disease, we do not necessarily capture those conditions that are most likely to have arrested growth. Second, the clinical observations relate largely to current conditions and abnormalities; they do not record medical histories. Since height reflects the cumulative effects of nutrition and disease, currently observed medical conditions are likely to be an imprecise indicator of the underlying disease burden.

The only measure that was recorded from the blood sample was the haemoglobin count. This is converted to a dummy equal to one if the haemoglobin count was less than $75 \%$ of the normal level, which was taken to be $14.8 \mathrm{~g}$ per $100 \mathrm{ml}$ of blood. Less than $11.1 \mathrm{~g}$ per $100 \mathrm{ml}$ is consistent with the World Health Organisation definition of anemia. This condition is associated with dietary deficiencies and in more severe cases it presents symptoms such as weakness, fatigue and shortness of breath. Using this

\footnotetext{
20 IV estimates (not reported) support the same conclusions.

21 In an important historical study Burstrom et al. (1999) find that, when controlling for socioeconomic status, the number of children in Swedish families in 1885-1910 was a significant determinant of death from measles but not from bronchitis or pneumonia. It seems likely that the latter would affect growth but would not necessarily result in death.

${ }^{22}$ For the analysis of disease incidence we take children aged from 1 to 14 . Unfortunately we lose another of the locations, Aberdeen, for which the results of clinical examinations are incomplete.
} 
Table 6

Relationship between medical conditions and height.

\begin{tabular}{|c|c|c|c|c|}
\hline & Anemia & Skeletal abnormality & Respiratory infection & Ear or eye infection \\
\hline Constant & $-0.001(0.04)$ & $0.004(0.20)$ & $0.020(1.01)$ & $0.012(0.66)$ \\
\hline Medical condition & $-0.188 \dagger(1.79)$ & $-0.037(0.74)$ & $-0.119(2.55)$ & $-0.199(2.86)$ \\
\hline $\mathrm{R}^{2}$ & 0.001 & 0.000 & 0.002 & 0.003 \\
\hline No of obs. & 2600 & 2912 & 2912 & 2910 \\
\hline
\end{tabular}

Note: Regressions on individuals aged $2-14$. 't' statistics in parentheses. ${ }^{* *}=$ significant at $1 \%$; ${ }^{*}=$ significant at $5 \%$; $\dagger=$ significant at $10 \%$.

Table 7

Effect of per capita income and number of children on disease incidence.

\begin{tabular}{|c|c|c|c|c|}
\hline & Anemia & Skeletal abnormality & Respiratory infection & Ear or eye infection \\
\hline Constant & $-0.15(0.9)$ & $-0.18(1.5)$ & $0.20 \dagger(1.7)$ & $-1.03^{* *}(7.0)$ \\
\hline Income per capita & $-0.10 \dagger(1.7)$ & $-0.08^{*}(2.2)$ & $-0.23^{* *}(5.6)$ & $-0.03(0.7)$ \\
\hline Number of children & $0.07^{* *}(2.8)$ & $0.03 \dagger(1.9)$ & $0.05^{* *}(3.3)$ & $0.10^{* *}(5.5)$ \\
\hline Average age & $-0.14^{* *}(6.6)$ & $-0.02^{*}(2.1)$ & $-0.05^{* *}(4.6)$ & $-0.002(0.2)$ \\
\hline Pseudo- $\mathrm{R}^{2}$ & 0.10 & 0.01 & 0.06 & 0.05 \\
\hline Likelihood ratio $\chi_{(3)}^{2}$ & 81.9 & 21.7 & 106.2 & 52.5 \\
\hline No. families & 1058 & 1134 & 1134 & 1134 \\
\hline Uncensored cases & 112 & 310 & 323 & 183 \\
\hline
\end{tabular}

Note: Tobit regressions of family average disease incidence, for children aged $1-14$. ' $t$ ' statistics in parentheses. ${ }^{* *}=$ significant at $1 \%$; $=$ significant at $5 \%$; $\dagger=$ significant at $10 \%$.

definition, of the 2839 children examined 5.0\% were anemic. The clinical observations also included a variety of skeletal disorders and abnormalities. Here we use the observations on frontal bossing, Harrison's sulcus and pigeon chest, which are markers of rickets, and we construct a dummy for the presence of any of these conditions. Of 3294 children examined $15.9 \%$ of the sample had at least one of these defects. ${ }^{23}$

The most important infections are respiratory infections of one kind or another. The clinical observations identified chronic upper respiratory catarrh, bronchitis and coryza, which is common cold or cold-like symptoms. Our measure of respiratory disease is the presence of any one of these conditions and it affected $19.1 \%$ of the 3294 children examined. Finally, the clinical examination also looked for eye and ear infections. The two eye conditions recorded are blepharitis, which is inflammation around the eye (particularly the eyelids) and conjunctivitis. The only ear condition that was recorded is otitis media, which is inflammation of the middle ear. We combine these observations into one dummy for any occurrence of eye or ear infection, which was present in $7.4 \%$ of the 3292 cases examined.

To what degree are these medical conditions related to the heights that were previously analysed? Table 6 shows the results of a regression of height $z$-scores on the four different groups of medical conditions recorded in the clinical examinations, estimated across the individuals for which both measures are available. The coefficients are all negative as would be expected but they should not be interpreted as causal. The first two columns show that height is negatively associated with anemia and with skeletal defects but in neither case is the relationship statistically significant. Perhaps the latter is not surprising since these conditions do not refer to the long bones such as the leg bones which are key determinant of height. The third and fourth columns reveal significant correlations between height and the incidence of respiratory disease or eye and ear infections. While these results are consistent with a link between infection and growth, the strength of these associations is relatively low. In all likelihood this is because we do not have evidence on some of the main conditions that limit growth, and we lack systematically obtained information on the full history of infections. ${ }^{24}$

In order to explore the link between household circumstances and medical conditions we present regressions relating each condition to the same explanatory variables that were used in the earlier analysis of heights. As before, in order to focus on the effects at the family level, for each disease outcome, we take the average across all the children in the household who were subject to examination. The resulting variable for the average disease or infection rate ranges between zero and one, and so we perform Tobit regression with censoring at the upper and lower bounds. Because some medical conditions are age-related we also include the average age of the children in the household. A variable for the sex composition was also introduced but was never significant and hence it is excluded from the reported regressions. ${ }^{25}$

Table 7 shows that for all the conditions analysed the sign of the coefficient on income per capita is negative while that on the number of children is positive. It also shows that the incidence of disease was generally negatively related to age. For anemia, the association with income per capita is weak while the association with the number of children is stronger. The reverse is true for skeletal abnormalities. Respiratory infections are more strongly related both to per capita income and to the number of children.

\footnotetext{
23 Some clinical observations were also made of knock knees and flat feet, but these are not included here, as they are not necessarily markers of disease.

24 However, the results are consistent with other evidence-see for instance Rona and Florey (1980) who examined the correlations between respiratory symptoms over the past year (as reported by parents) and heights of British children in the early 1970s.

${ }_{25}$ These variables were not included in the earlier regressions because the $z$-scores for height adjust for sex and year of age.
} 
Table 8

Effect of per capita food expenditure, overcrowding and cleanliness on disease incidence.

\begin{tabular}{|c|c|c|c|c|}
\hline & Anemia & Skeletal abnormality & Respiratory infection & Ear or eye infection \\
\hline Constant & $0.39(1.6)$ & $-0.04(0.19)$ & $0.04(0.2)$ & $-0.45^{*}(2.5)$ \\
\hline Per capita food expenditure & $-0.15^{* *}(2.7)$ & $-0.10^{* *}(2.8)$ & $-0.08^{*}(2.1)$ & $-0.11^{* *}(2.9)$ \\
\hline Overcrowding (persons per room) & $0.02(0.6)$ & $0.05(1.6)$ & $0.17^{* *}(5.4)$ & $0.09^{* *}(2.8)$ \\
\hline Cleanliness index & $-0.16^{*}(2.1)$ & $-0.06(1.1)$ & $-0.10^{* *}(1.8)$ & $-0.14^{*}(2.4)$ \\
\hline Average age & $-0.11^{* *}(5.9)$ & $-0.01(1.0)$ & $-0.033(2.92)$ & $0.02(1.6)$ \\
\hline Pseudo- $\mathrm{R}^{2}$ & 0.10 & 0.02 & 0.048 & 0.04 \\
\hline Likelihood ratio $\chi^{2}(3)$ & 69.1 & 23.8 & 75.91 & 41.8 \\
\hline No. families & 923 & 990 & 990 & 990 \\
\hline Uncensored cases & 100 & 269 & 283 & 165 \\
\hline
\end{tabular}

Note: Tobit regressions of family average disease incidence, for children aged $1-14$. ' $\mathrm{t}$ ' statistics in parentheses. ${ }^{* *}=$ significant at $1 \%$; ${ }^{*}=$ significant at $5 \%$. The number of observations is reduced from that in Table 7 because of missing data on expenditure class and persons per room.

Eye and ear infections are strongly associated with family size, but not with income per capita. These results suggest that family size was particularly important for infectious diseases, consistent with the idea that larger families created adverse disease environments by increasing the rate of infection.

Table 8 probes a little deeper into the channels of influence by testing the associations with food expenditure, overcrowding and cleanliness. The first column indicates that anemia is strongly associated with per capita food expenditure but not with overcrowding. This makes sense as anemia is chiefly associated with dietary deficiency. Skeletal abnormalities are also inversely associated with per capita food expenditure but there is only a weak positive association with overcrowding. By contrast respiratory infections are strongly positively associated with overcrowding as well as inversely associated with food expenditure per capita. This result parallels that for the number of children in Table 7. It suggests that the spread of infection within the household was greater the more crowded the house. That finding is replicated for ear or eye infections which are also likely to have been passed between individuals in the household. The effect of cleanliness, while always giving the expected sign is only significant at the $5 \%$ level for anemia and for ear and eye infections.

The results reported in this section offer some support for the argument that the variables that determine heights are also associated with the disease environment in the household. Although the inferences are necessarily limited, they provide some corroborative evidence for an association between the degree of crowding and the spread of infectious disease. This in turn suggests that the negative effect of the number of children in the household on their average height that was reported in Tables 3 and 5 operates partly through the channel of recurrent infections arresting growth.

\section{Explaining heights 1886-1938}

As mentioned earlier, the evidence indicates a steep increase in heights from the turn of the century onwards. Here we use our results on heights to 'explain' that improvement. As noted earlier, the households in the Boyd Orr cohort are more representative of living standards a generation earlier, which can be considered a strength for the purposes of backcasting. Of course we must be careful in inferring the causes of change over time based on coefficients estimated from a cross-section. If the effects of household income and family size become smaller as knowledge of nutrition and hygiene disseminates, and as the general disease environment improves, then our estimates for the late 1930s will understate the average effects for the previous half century. ${ }^{26}$ Similarly, our projections will be too modest if changes in family income have decreasing effects as households become richer (Steckel, 2009, p. 142), although we find no evidence of this. Nevertheless, in order not to overstate the effects over time we use the relevant OLS coefficients, which are more precisely estimated and which, if anything, are biased towards zero.

In order to trace the likely effects of changing income and family composition over time and to be consistent with the families in the Boyd Orr cohort we focus on a standard family type-working class male-headed households with a non-working wife and at least one child present, counting as children all those under 18. Table 9 offers some stylised facts for this classic family type and the basis for these calculations is given in the notes to the table. The dates chosen are those of the Board of Trade or Ministry of Labour wage surveys of 1886, 1906 and 1938. The latter two dates are also close to the surveys of working class budgets undertaken in 1904 and 1938. The calculations in the fourth row of Table 9 show dramatic increases in family income per capita, which was due to the combination of increasing real earnings and decreasing family size.

Calculations of the possible effects of these changes appear in Table 10. Taking an increase of one income category in the Boyd Orr survey to be worth five shillings, the increase in per capita income between 1906 and 1938 would be equivalent to 6.2/ $5=1.24$. Using the coefficient in the third column of Table 3 , the effect of rising income per capita increased height by $0.258 \times 1.24=0.32$ standard deviations. The direct effect of falling family size increased heights by $(-) 0.073 \times(-) 1.6=0.12$ standard deviations. The total effect of $0.32+0.12=0.44$ standard deviations equates to an increase in height of $2.6 \mathrm{~cm}$ for eightyear olds and it accounts for about two fifths of the increase in heights between 1906 and 1938. The effect of falling family size alone (holding wage rates constant at the 1906 level but allowing supplementary earnings to decline as family size decreases)

\footnotetext{
${ }^{26}$ We find no evidence of non-linearity in the effects of per capita income in our data. Adding the square of income per capita in column 3 of Table 3 gives a coefficient of 0.03 (' $\mathrm{t}$ ' $=0.82$ ). But since income per capita is a categorical variable this is not a very strong test.
} 
Table 9

Trends in working class families, 1886-1938.

\begin{tabular}{|c|c|c|c|c|c|}
\hline & 1886 & 1906 & 1938 & Change 1886-1906 & Change 1906-38 \\
\hline No of children & 4.5 & 3.6 & 2.0 & -0.9 & -1.6 \\
\hline No in family & 6.5 & 5.6 & 4.0 & -0.9 & -1.6 \\
\hline Family income (1938 shillings) & 55.7 & 62.9 & 69.6 & 7.2 & 6.7 \\
\hline Per capita income (shillings) & 8.6 & 11.2 & 17.4 & 2.7 & 6.2 \\
\hline Food expenditure (shillings) & & 37.7 & 34.8 & & -2.9 \\
\hline Per capita food expenditure & & 6.7 & 8.7 & & 2.0 \\
\hline Overcrowding: persons per room & & 1.1 & 0.9 & & -0.2 \\
\hline
\end{tabular}

Notes: The standard working class family is taken to be a male breadwinner household with a non-working wife and children under age 18 . The data in Table 8 were derived for this standard family in England and Wales as follows:

Number of children per family. The 1904 survey of working class budgets, which covered 'normal' families with a male breadwinner and at least one child, records an average of 3.6 children of all ages (Bowley, 1941, p. 129); The number of children under 16 in families with any children can be calculated from Gazeley and Newell (2007 Table 10; 2009 Table 6) as 3.29 in 1904 and 1.87 in 1938 . Raising these figures by $10 \%$ to allow for those aged 16 and 17 gives totals of 3.6 for 1904 and 2.0 for 1938 . The figure for 1886 is estimated at 4.5 by extrapolation using census-based data kindly supplied by Mike Murphy.

Earners and earnings per family. Weekly earnings for adult males, based on the periodic wage enquiries, were taken from Bowley (1937, p. 49 ): $24 \mathrm{~s}$ in $1886,29 \mathrm{~s}$ in 1906 and $60 \mathrm{~s}$ in 1938. Assuming that children aged $14-17$ were $20 \%$ of all children and earned $40 \%$ of the adult wage, supplementary earners would have contributed an additional $26 \%$ in $1886,22 \%$ in 1906 and $14 \%$ in 1938 . The 1904 survey of working class budgets recorded average weekly family income of 36 s 10 d, or $27 \%$ more than the adult male wage; for 1936 Rowntree (1941, p. 129) found that supplementary earners added $14.3 \%$. The estimated family incomes were converted to 1938 prices using the cost of living index (Feinstein, 1995, p. 264-5).

Expenditure on food. The working class families surveyed in 1904 spent $60 \%$ of their income on food (Bowley 1941, p. 131). In the 1938 survey only $40 \%$ was spent on food but this included a wider range of household types (in particular households without children). The figure would have been higher for the standard family and so we estimate a food share for 1938 at $50 \%$.

Persons per room. In 1931 the average number of persons per room was 0.85 for a family of $4,1.03$ for a family of 5 , and 1.20 for a family of 6 . Since families with children experienced somewhat greater crowding we assume a figure of 1.0 for 1938 . Unfortunately we do not have comparable figures for 30 years earlier. However, the average number of persons per room in four-roomed dwellings across all family types fell from 1.12 per room in 1901 to 0.95 in 1931 . Allowing for changes in family size it seems reasonable to assume a decrease in crowding of about 0.2 persons per room over the 30 year period.

increases height by $1.6 \mathrm{~cm}$. Thus about three fifths of the explained part of the increase in heights is due to the direct and indirect effects of the fall in the number of children, which therefore accounts for around a quarter of the total observed increase.

Similar calculations for the period from 1886 to 1906 indicate that growth in per capita income added around $0.8 \mathrm{~cm}$ to the height of the average eight-year old while the separate effect of falling family size contributed $0.4 \mathrm{~cm}$. Although we lack precise estimates of the increase in children's heights over this period it seems likely the total effect, $1.2 \mathrm{~cm}$, would account for a very substantial share of it, perhaps as much as three quarters. More than half of the explained part is due to falling family size (holding wage rates constant).

Two observations flow from these calculations. First, over the half century from 1886 changes in per capita income and family size increased the height of eight-year olds by $3.8 \mathrm{~cm}$, with about $2.3 \mathrm{~cm}$, or around three fifths of the total explained increase, due to falling family size. The second point is that falling family size also contributed to the acceleration in heights, starting at zero before the 1880s, adding $0.3 \mathrm{~cm}$ per decade from then up to 1906 and $0.5 \mathrm{~cm}$ per decade from 1906 to 1938 . But after the turn of the century declining family size and increasing real income explain a smaller share of the gains in height, leaving more room for other influences such as improved knowledge of child health and nutrition as well as improvements in sanitation and housing infrastructure. $^{27}$

It is interesting also to consider predictions over time from the estimates that include per capita food expenditure and persons per room. These are more speculative because there is a greater element of choice over expenditure on food, housing and other goods. Here we apply the coefficients in the first column of Table 5 to the estimated changes reported in Table 9. For the classic family with children we estimate that between 1906 and 1938 the growth in food expenditure per capita added about $1.6 \mathrm{~cm}$ while the fall in persons per room contributed just $0.1 \mathrm{~cm}$. About two thirds of the total effect is accounted for by the falling family size.

The predictions based on food expenditure and persons per room 'explain' rather less of the increase in heights than those based on income per capita and the number of children. This is probably because the former fails to reflect the improvement in the quality of housing, some of which is captured in the effects of cleanliness and housing conditions that feature in Table 5. How such qualitative variables might have evolved is difficult to judge. In his surveys of York Rowntree (1941, p. 225-6) found that between 1899 and 1936 the share of working class families living in slums fell from 25.5\% to 11.3\%, while those living in the best quality housing increased from $12.7 \%$ to $34.1 \%$. Much of the progress in housing quality was due to the postwar building program of York

\footnotetext{
${ }^{27}$ Although not the focus of this paper, it is worth considering what happened in the decades after 1938 when heights continued to increase despite the rebound in family size associated with the postwar baby boom. While it is tempting to suggest that the family size effect faded out, studies of the 1958 birth cohort indicate otherwise (Goldstein, 1971; Fogelman, 1975). Between 1938 and 1958 real wages grew by 49\%, and the number of children increased by about 1.0. That would imply an increase of $1.5 \mathrm{~cm}$ due to per capita family income and a reduction of $04 \mathrm{~cm}$ due to the separate effect of the number of children. Thus the income effect dominates but the combined effects are smaller than during the interwar period. However, the health of children and are likely to have been enhanced by a variety of welfare and medical improvements that came into effect in the early postwar period.
} 
Table 10

Effects of family income and family size on heights, 1886-1938.

\begin{tabular}{|c|c|c|c|c|}
\hline \multirow[t]{2}{*}{ Change in } & \multicolumn{2}{|c|}{ Change 1886-1906 } & \multicolumn{2}{|c|}{ Change 1906-38 } \\
\hline & SD & $\mathrm{cm}$ & SD & $\mathrm{cm}$ \\
\hline Family income per capita & 0.14 & 0.8 & 0.32 & 1.9 \\
\hline No in family & 0.07 & 0.4 & 0.12 & 0.7 \\
\hline Total & 0.21 & 1.2 & 0.44 & 2.6 \\
\hline Of which due to family size & 0.11 & 0.7 & 0.27 & 1.6 \\
\hline Per capita food expenditure & & & 0.26 & 1.6 \\
\hline Overcrowding: persons per room & & & 0.02 & 0.1 \\
\hline Total & & & 0.28 & 1.7 \\
\hline
\end{tabular}

Source: Based on data in Table 5 and coefficients in col. (3) of Table 3 and col. (1) in Table 5. The total contribution of family size is calculated by holding adult earnings constant at the beginning period value but adjusting the change in income to allow for the contribution of older children. The effect of the change in (adjusted) income per capita due only to falling family size is then added to the direct effect.

Corporation and it seems likely that such developments contributed to the remarkable improvement in the health of children in the decades following the First World War. ${ }^{28}$

As noted earlier, improvement in the disease environment is reflected in the dramatic falling infant mortality. Analysing time series data for average heights of schoolchildren in British towns Hatton (2009) finds that the local infant mortality rate had a negative effect on subsequent heights of children. On these results, the fall in infant mortality between 1901-5 and 1941-5 accounts for an increase in heights of about $0.6 \mathrm{~cm}$ per decade, or a little over a quarter of the total increase in the heights of 6-9 year olds. These effects cannot simply be added to those reported in Table 10, as some of the decline in infant mortality would ultimately be due to increasing family incomes and falling family size. Nevertheless the results do underline the fact that improvements both in nutrition and in the disease environment contributed to the trend increase in the heights of children.

\section{Conclusion}

Using a unique survey of working class families for the late 1930s we have found that the heights of children are positively related to income per capita and negatively related to the number of children in the family. These effects can be further decomposed into those factors that are associated with nutrition and those that are associated with disease, both of which affect growth during childhood. While nutrition is mainly associated with per capita expenditure on food, the spread of infectious disease within the household was exacerbated by overcrowding and poor quality housing. Our examination of medical conditions suggests that infectious diseases were closely associated with the degree of crowding within the household. Thus the number of siblings in the family negatively affected the health of children, both through reducing per capita food expenditure and by worsening the disease environment.

These findings suggest an answer to the puzzle of why the health of children (and their subsequent outcomes as adults) improved so dramatically in the first half of the twentieth century. All the evidence points to a distinct acceleration in the rate of increase in the heights of children around age 8-10, from less than $1 \mathrm{~cm}$ per decade in the late nineteenth century to more than $2 \mathrm{~cm}$ per decade in the first half of the twentieth century. In the late nineteenth century rising incomes brought better nutrition, with consequent improvements in health and height. But the external disease environment improved only slowly as the effect of public health improvements were offset by growing urbanization and increasing population density. This is reflected in the fact that while child mortality rates fell as a result of improved nutrition, the infant mortality rate remained obstinately high.

In the first half of the twentieth century real wages increased no faster on average than they had in the previous half century. Yet the dramatic fall in fertility meant that, for households with children, income per capita increased more strongly and poverty rates declined more rapidly than they would have otherwise. It also meant an improvement in the disease environment within the household as the degree of crowding decreased. More rapid improvements in urban infrastructure, in housing quality, and in practical knowledge of hygiene probably explain most of the improvement in child health that is not accounted for by rising family income and falling family size. But improvements in medical technology contributed little, because the discovery or diffusion of most of the new medical treatments came too late to confer much benefit on working class families until after the Second World War. Taken together, these trends suggest that unless we recognise the effect of falling family size it is difficult to fully account for the sharp improvements in child health in the half century before the advent of the National Health Service.

\section{Acknowledgments}

We are grateful for useful comments from Alison Booth, George Davey Smith, Mike Murphy, Roderick Floud, Ian Gazeley, Richard Steckel, Mark Thomas, Jeff Williamson, Chikako Yamauchi, and participants at the Economic History Association Conference (New Haven 2008), the conference on Long-term Implications of the Demographic Transition (Madrid 2009) and seminars at Australian National University, Monash University and the University of Melbourne. We also thank two anonymous referees.

\footnotetext{
${ }^{28}$ According to the coefficients in the last column of Table 5, increasing housing quality, as measured by ventilation, by one class, e.g. from 'moderate' to 'good' would increase average height by about $1 \mathrm{~cm}$. This is equivalent to the effect of increasing food expenditure per capita by about $1 \mathrm{~s} 2 \mathrm{~d}$ a week.
} 


\section{Appendix A. First stage estimates for Table 3 col. 4}

\begin{tabular}{lcc}
\hline & Income per capita & No. of children \\
Constant & $0.75(1.2)$ & $4.03^{* *}(11.4)$ \\
Twins last birth & $-0.42^{* *}(3.4)$ & $1.40^{* *}(4.3)$ \\
Occupational income & $0.02^{* *}(15.7)$ & $-0.01^{* *}(5.9)$ \\
Share of labor force in agriculture & $-0.70^{* *}(2.9)$ & $-0.99^{*}(2.0)$ \\
Share of population urban & $-0.26 \dagger(1.8)$ & $0.49(1.6)$ \\
Local unemployment rate & $-0.01(1.2)$ & $0.04^{* *}(2.9)$ \\
$\mathrm{R}^{2}$ & 0.27 & 0.08 \\
$\mathrm{~F}$ & 59.0 & 22.5 \\
No. of observations & 1102 & 1102 \\
\hline
\end{tabular}

Note: t-statistics in parentheses. ${ }^{* *}=$ significant at $1 \% ;{ }^{*}=$ significant at $5 \% ; \dagger=$ significant at $10 \%$. As none of the instruments appear in the second stage, the $\mathrm{R}^{2}$ reported here is the partial $\mathrm{R}^{2}$ for excluded instruments and the F-statistic is the test for excluded instruments.

Sources for instruments: Occupational income is constructed by allocating a value to each of the six social classes recorded for the households in the Boyd Orr survey on the basis of the occupational class of the head of household. A weekly income for each class was calculated from the data reported by Routh (1965) p. 104. This in turn was derived from the Ministry of Labour's earnings survey for 1935/6. Other variables are based on the locality. The share of the labour force in agriculture and the share of the population urban are measured at the county level, taken from the 1931 census. The unemployment rate is the average unemployment rate of adult males for 1937-9, based on the Ministry of Labour's local unemployment index. These are for employment exchange areas and are reported in the Ministry of Labour Gazette.

\section{References}

Beard, A.S., Blaser, M.J., 2002. The ecology of height: the effect of microbial transmission on human height. Perspectives in Biology and Medicine 45, 475-498. Baten, J. (2007), “Global height trends in industrial and developing countries, 1810-1984: an overview," Unpublished paper: University of Tübingen. Becker, G.S., Lewis, H.G., 1973. On the interaction between the quantity and quality of children. Journal of Political Economy 81, S279-S288.

Becker, G.S., Tomes, N., 1976. Child endowments and the quantity and quality of children. Journal of Political Economy 84, S143-S162.

Bell, F., Millward, R., 1998. Public health expenditures and mortality in England and Wales, 1870-1914. Continuity and Change 13, 221-249.

Booth, A.L., Kee, H.J., 2009. Birth order matters: the effect of family size and birth order on educational attainment. Journal of Population Economics 22, $367-397$. Bowley, A.L., 1937. Wages and Income in the United Kingdom since 1800. Cambridge University Press, Cambridge.

Bowley, A.L., 1941. Earnings and prices, 1904, 1914 and 1937-38. Review of Economic Studies 8, 129-142.

Boyd Orr, J., 1936. Food Health and Income: A Survey of Adequacy of Diet in Relation to Income. Macmillan, London.

Boyne, A.W., Aitken, F.C., Leitch, I., 1957. Secular change in height and weight of British schoolchildren, including an analysis of measurements of English children in primary schools: 1911-1953. Nutrition Abstracts and Reviews 27, 1-18.

Burstrom, B., Diderichsen, F., Smedman, L., 1999. Child mortality in Stockholm during 1885-1910: the impact of household size and number of children in the family on risk of death from measles. American Journal of Epidemiology 149, 1134-1141.

Cage, R.A., Foster, J. 2002. Overcrowding and infant mortality: a tale of two cities. Scottish Journal of Political Economy 49, 129-149.

Clements, E.M.B., 1953. Changes in the mean stature and weight of British children over the past seventy years. British Medical Journal 897-902 October 24th. Cutler, D., Miller, G., 2005. The role of public health improvements in health advances: the twentieth century United States. Demography 42, 1-22.

Dyhouse, C., 1978. Working class mothers and infant mortality in England, 1895-1914. Journal of Social History 12, 248-267.

Elo, I.T., Preston, S.H., 1992. Effects of early life conditions on adult mortality: a review. Population Index 58, 186-212.

Feinstein, C.H., 1995. Changes in nominal wages, the cost of living and real wages in the United Kingdom over two centuries. In: Scholliers, P., Zamagni, V. (Eds.), Labour's Reward. Edward Elgar, Aldershot.

Fildes, V., 1998. Infant feeding practices and infant mortality in England, 1900-1919. Continuity and Change 13, 251-280.

Floud, R., 1994. The heights of Europeans since 1750: a new source for European economic history. In: Komlos, J. (Ed.), Stature, Living Standards and Economic Development. University of Chicago Press, Chicago.

Floud, R., Wachter, K., Gregory, A., 1990. Height, Health and History: Nutritional Status in the United Kingdom, 1750-1980. Cambridge University Press, Cambridge. Fogel, R.W., 2004. Escape from Hunger and Premature Death, 1700-2100. Cambridge University Press, Cambridge.

Fogelman, K.R., 1975. Developmental correlates of family size. British Journal of Social Work 5, 43-57.

Galobardes, B., Lynch, J.W., Davey Smith, G., 2004. Childhood socioeconomic circumstances and cause-specific mortality in adulthood: systematic review and interpretation. Epidemiologic Reviews 26, 7-21.

Garrett, E., Reid, A., Schürer, K., Szreter, S., 2001. Changing family size in England and Wales: place, class and demography, 1891-1911. Cambridge University Press, Cambridge.

Gazeley, I., Newell, A., 2007. Poverty in Britain in 1904: an early social survey rediscovered. IZA Discussion Paper No. 3046. IZA, Bonn.

Gazeley, I., Newell, A., 2009. The end of destitution. IZA Discussion Paper No. 4295. IZA, Bonn.

Goldstein, H., 1971. Factors influencing the height of seven year old children: results from the National Child Development Study. Human Biology 43, 92-111.

Gunnell, D., Davey Smith, G., Frankel, S., Nanchahal, K., Braddon, F.E., Pemberton, J., Peters, T.J., 1998a. Childhood leg length and adult mortality: follow up of the Carnegie (Boyd Orr) Survey of Diet and Health in Pre-war Britain. Journal of Epidemiology and Community Health 52, 142-152.

Gunnell, D., Davey Smith, G., Holly, J.M.P., Frankel, S., 1998b. Leg length and risk of cancer in the Boyd Orr cohort. British Medical Journal 317, $1350-1351$.

Haines, M.R., 2004. Growing incomes, shrinking people-can economic development be hazardous to your health? Social Science History 28, 249-270.

Hanusheck, E., 1992. The trade-off between child quality and quantity. Journal of Political Economy 100, 894-917.

Harris, B., 1994. The height of schoolchildren in Britain, 1900-1950. In: Komlos, J. (Ed.), Stature, Living Standards and Economic Development. University of Chicago Press, Chicago, pp. 25-38.

Harris, B., 1995. The Health of the Schoolchild: A History of the School Medical Service in England and Wales. Open University Press, Buckingham.

Hatton, T.J., Martin, R.M., 2010. The effects on stature of poverty, family size and birth order: British children in the 1930s. Oxford Economic Papers 62, 157-184.

Hatton, T. J. (2009), "Infant mortality and the health of survivors: Britain 1910-1950," Unpublished paper, Australian National University.

Humphries, J., 2007. 'Because they are too menny...' children, mothers, and fertility decline: the evidence from working-class autobiographies of the eighteenth and nineteenth centuries. In: Janssens, A. (Ed.), Gendering the Fertility Decline in the Western World. Peter Lang, Bern, pp. 113-150.

Jackson, R.V., Thomas, M., 1995. Height, weight and wellbeing: Sydney schoolchildren in the early twentieth century. Australian Economic History Review 35 , 39-65.

Johnson, P.A., Nicholas, S., 1997. Health and welfare of women in the United Kingdom, 1795-1920. In: Steckel, R.H., Floud, R. (Eds.), Health and Welfare during Industrialization. University of Chicago Press, Chicago.

Karn, M.N., 1937. Summary of results of investigations into the height and weight of children in the British working classes during the last hundred years. Annals of Eugenics 7, 376-398. 
Lee, C.H., 1991. Regional inequalities in infant mortality in Britain, 1861-1971: patterns and hypotheses. Population Studies 45, 55-65.

Martin, R.M., Gunnell, D., Pemberton, J., Frankel, S., Davey Smith, G., 2005. Cohort profile: the Boyd Orr cohort-an historical cohort study based on the 65 year follow-up of the Carnegie Survey of Diet and Health (1937-39). International Journal of Epidemiology 34, 742-749.

McKeown, T., 1976. The Modern Rise of Population. Edward Arnold, London.

McKeown, T., Record, R.G., Turner, R.D., 1975. An interpretation of the decline of mortality in England and Wales during the twentieth century. Population Studies 29, 391-422.

Millward, R., Bell, F., 1998. Economic factors in the decline of mortality in late nineteenth century Britain. European Review of Economic History 2, 263-288.

Millward, R., Bell, F., 2001. Infant mortality in Victorian Britain: the mother as medium. Economic History Review 54, 699-733.

Mokyr, J., 2000. Why “more work for mother?” Knowledge and household behavior, 1870-1945. Journal of Economic History 60, $1-41$.

Office of Population Censuses and Surveys (OPCS), 1987. Birth Statistics: Historical Series of Statistics from Registrations of Births in England and Wales, 1837-1983. HMSO, London.

Preston, S., Haines, M., 1991. The Fatal Years: Child Mortality in Late Nineteenth Century America. Princeton University Press, Princeton.

Registrar General, 2004. Mortality Statistics: Review of the Registrar General on Deaths in England and Wales. HMSO, London.

Reves, R., 1985. Declining fertility in England and Wales as a major cause of the twentieth century decline in mortality. American Journal of Epidemiology 122, $112-126$.

Riggs, P., 1994. The standard of living in Scotland, 1800-1850. In: Komlos, J. (Ed.), Stature, Living Standards and Economic Development. University of Chicago Press, Chicago.

Rona, R.J., Florey, C. duV, 1980. National study of health and growth: respiratory symptoms and height in primary schoolchildren. International Journal of Epidemiology 9, 35-43.

Routh, G., 1965. Occupation and Pay in Great Britain, 1906-1960. Cambridge University Press, London.

Rowett Institute, 1955. Family Diet and Health in Pre-war Britain. Carnegie UK Trust, Dunfermline.

Rowntree, B.S., 1901. Poverty: A Study of Town Life. Macmillan, London.

Rowntree, B.S., 1941. Poverty and Progress: A Second Social Survey of York. Longmans Green, London.

Rosenbaum, S., 1988. 100 years of heights and weights. Journal of the Royal Statistical Society, Series A 151, $276-309$.

Scott, P., 2008. Did owner occupation lead to smaller families for interwar working-class households? Economic History Review 61, 99-124.

Steckel, R.H., 1995. Stature and the standard of living. Journal of Economic Literature 33, 1903-1940.

Steckel, R.H., 2009. Heights and human welfare: recent developments and new directions. Explorations in Economic History $46,1-23$.

Steckel, R.H., Floud, R. (Eds.), 1997. Health and Welfare during Industrialization. University of Chicago Press, Chicago.

Weir, D.R., 1993. Parental consumption decisions and child health during the early French fertility decline, 1790-1914. Journal of Economic History 53, 259-274.

Whitwell, G., de Souza, C., Nicholas, S., 1997. Height, health and economic growth in Australia, 1860-1940. In: Steckel, R.H., Floud, R. (Eds.), Health and Welfare during Industrialization. University of Chicago Press, Chicago. 1997.

Williamson, J.G., 1990. Coping with City Growth during the British Industrial Revolution. Cambridge University Press, Cambridge.

Woods, R.I., Watterson, P.A., Woodward, J.H., 1988. The causes of rapid infant mortality decline in England and Wales, 1861-1921, part I. Population Studies 42, 343-366. 